\title{
The Computer Aided Methods for Tie Dyeing Pattern
}

\author{
Jianxia Su ${ }^{1, a}$, Zhao $\mathrm{Li}^{2, \mathrm{~b}}$, Xiaodong Sun ${ }^{3, \mathrm{c}}$ \\ ${ }^{1}$ Information Engineering School of Beijing Institute of Fashion Technology, Beijing, China \\ ${ }^{2}$ Beijng Jiaotong University, Beijing, China \\ ${ }^{3}$ Center of Beijing Institute of Fashion Technology, Beijing, China \\ a gxysujx@bift.edu.cn, ${ }^{b} 738577720 @ q q . c o m,{ }^{c}$ jsjsxd@bift.edu.cn
}

Keyword:Tie Dyeing. Fractal Geometry. Computer Simulation, Digital Pattern

\begin{abstract}
Basing on the analyzing of Tie dying art, pattern, and feature, Tie Dyeing computer simulation is proposed in this paper. and the fractal theory imitative transformation, and iterated function system with probability are presented with some experiments of classic patterns and parameters.
\end{abstract}

\section{Introduction}

The emergence of digital printing and dyeing technology has greatly changed the traditional textile industry production mode, which in turn has changed the way people to the consumption of textiles and ideas. At the same time, China's textile and garment industry is going to establish a rapid response and provide the technical support for supply chain management thinking, the textile and garment industry information construction one step further, also beneficial influence on the art design education mode change. But pollution is serious, not only the traditional printing and dyeing industry and the production cycle is long and complex process, the equipment investment is big, cannot provide small batch and many varieties of products. At present, consumers are increasingly demanding on textile and apparel fabrics, personalization, costliness, and health care, comfort, environmental protection has become the development trend of textile and apparel fabrics. The traditional printing and dyeing finishing technology has far can not adapt to the needs of society. Digital printing digital printing machine, dyeing machine, textile CAD/CAM, the related auxiliary materials, e-commerce and other high and new technology and new equipment, new materials. It will change the pattern of traditional production of textile printing and dyeing industry, so as to adapt to the personalized, small batch, fast reaction of market needs

Today digital art design is developed very quickly, and with the development of the computer technology digital art had become a mainstream, graphic design or pattern design is widely used in the design of the textile pattern, a variety of computer method for graphic design, as well as textile pattern design created a new train of thought.

\section{Software methods to design the digital tie dyeing pattern}

\section{The combination of Photoshop and Illustrator}

Generally speaking, there are two kinds of methods to generate the effect of tie dying pattern, one is using some special software. Another is using programming technology.

The combination of Photoshop software and Illustrator software. and Symmetry plug-in. the detail is in Photoshop software environment, form the basic JPG picture. And in Illustrator software and with the Symmetry plug-in to form the digital tie dying picture. Fig. 1 is the JPG picture done by Photoshop Software, after that Fig. 1 is used in Illustrator software, and processed by Symmetry plug-in. Fig. 2 is the digital Tie Dying picture finally. 


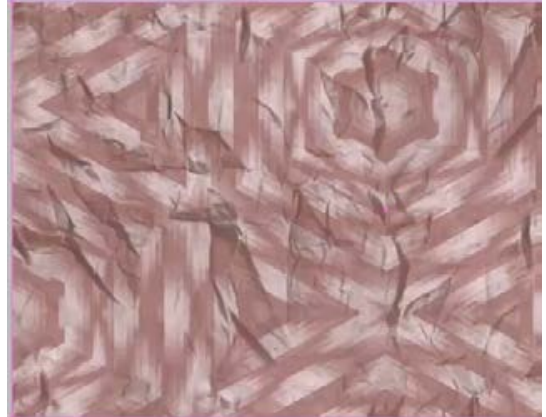

Fig. 1

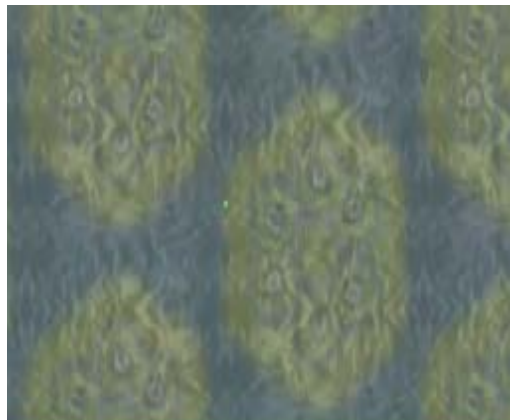

Fig. 2

Kaleidoscope Software Used to Simulate the Tie Dying Pattern

A kaleidoscope is an optical toy, using prism reflection to see patterns of symmetric constantly changing, wonderful, and is one of the many childhood favorite toys. The kaleidoscope software will simulate the prism moves in the background image, and then the real-time generation and display the "Kaleidoscope" pattern. Bye changing the parameters, software works are showed as follows:

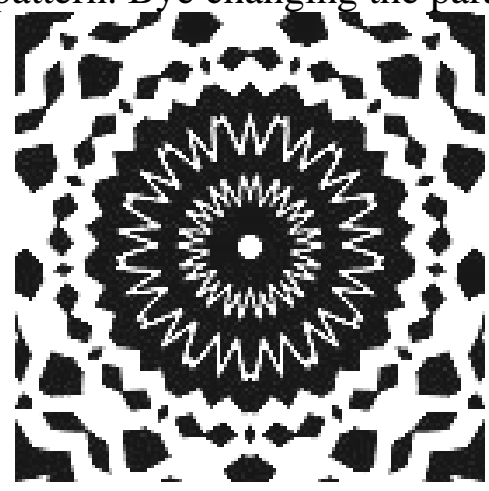

Fig. 3

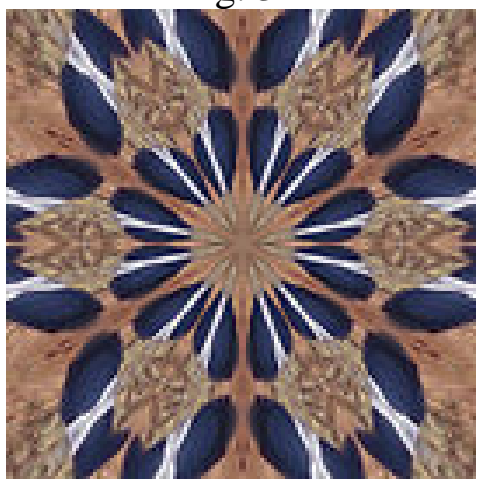

Fig. 5

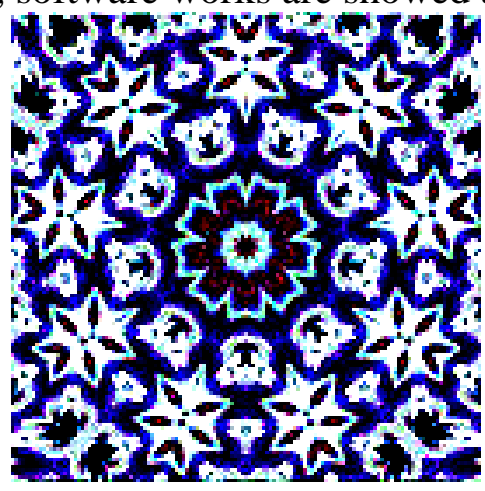

Fig. 4

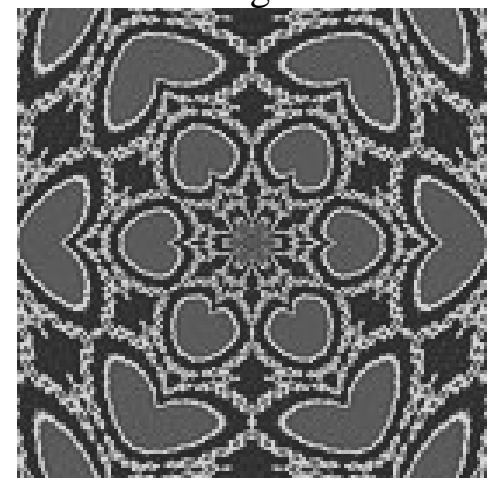

Fig. 6

\section{Processing software}

The name of the open source programming language is 'processing'. It can be downloaded from Processing.org. It is used to generate images, animation and interactive software programming language.

The basic programming thought is that code will be generated on the screen of a circle. Add some code can follow the mouse go round. If adding some code, the circle will be with a click of the mouse to change color. a line is wrote, and add a line, the effect of increased. The result is a fragment program synthesis.

Processing is a new computer language has the revolutionary forward-looking concept. It is to introduce the programming language in the electronic arts environment, and introduce the concept of electronic art to the program designer. It is the extension of Java language, and support many of the current Java language structure, but syntactically simple many design and has many thoughtful and humane.

A simulated design pattern is showed as Fig.7 


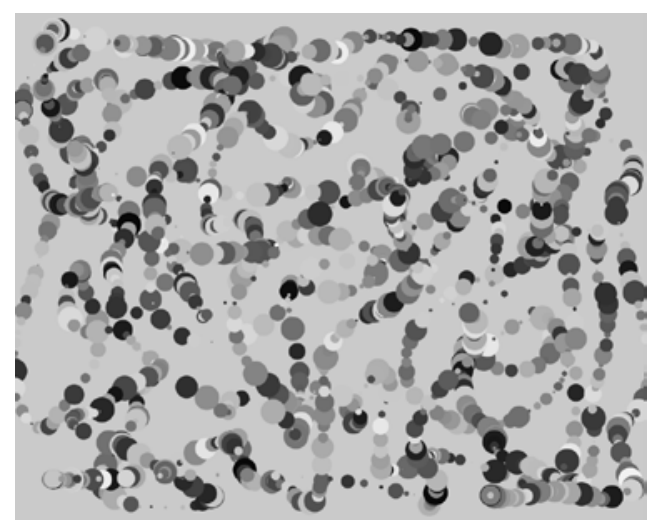

Fig. 7

\section{Programming method}

The second method is programming, This method is also the most difficult one at present, the combination computer program languages and Opengl and Fractal to simulate the digital picture of Tie Dying. the work is still going on now. Most of the programming works are related to Computer Graphics. The programming ideas had formed, but programming is time-consuming and laborious, most of the program has not finished, The programming work will be showed in the following paper. Work on this subject is still going on.

\section{Summary}

Design of digital textile Tie Dying patterns through the computer software provides tools, graphics, and image processing function and directly on a computer drawing pattern. Or by putting a programming method to obtain patterns, the application of digital technology in the modem textile pattern design, create a new pattern style.

\section{Acknowledgments}

This paper is sponsored by KYJH02140201/025 of 2014 project of Beijing Science and Technology and this study is also funded by 2014 Undergraduate Training Programs of Beijing Institute of Fashion Technology and number 067135300100 of Beijing Project.

\section{References}

[1] Tong Tianxiang,Lin xia.New view of nature water. Central Party School Press,Beijing (1998)

[2] Xu Zhijun, Zhu Qipeng,Wu Feng. China diffusion - reaction set limit fractal aggregation model. Exploration of Nature ,17 ( 2 ) :81 -82 (1998)

[3] Zhang,Y.P.The Pattern of Tie Dyeing and Its Chareacteristics of Making Shanghai-Frank/art

[4] Ai Nanshan, Chen Rong, Li Houqiang. Towards fractal geomephology. Geography and Territorial Research, 15 ( 1 ) :92 -96(1999) chapter, 10, Kluwer Academic Publishers (2000).

[5] Hu,X.N 2006 Analysis on the developing tendency of modern garment industry..Progress in Texile Science \& Technology 3:10-12

[6] Wang,S.T 2009.Computer-aided Design Tie-dye Graphics.Process in Textile Science \& Technology 4:48-49,56

[7] Information on http://www.processing.gov 